\title{
ENRAIZAMENTO DE ESTACAS LENHOSAS DE PEREIRA TRATADAS COM AIB E MANTIDAS EM AMBIENTE DE ESTUFA TIPO B.O.D. E DE TELADO ${ }^{1}$
}

\author{
WILSON BARBOSA ${ }^{2}$, RAFAEL PIO ${ }^{3}$, NELSON PIRES FELDBERG $^{4}$, EDVAN ALVES CHAGAS $^{5}$, \\ RENATO FERRAZ DE ARRUDA VEIGA ${ }^{2}$
}

RESUMO - Pesquisou-se o enraizamento da pereira em ambiente controlado de estufa tipo B.O.D. e em telado simples. Utilizou-se a cultivar híbrida 'Limeira', destinada exclusivamente para fins culinários e para porta-enxerto. Estacas lenhosas sem folhas, medindo 25 $\mathrm{cm}$ de comprimento, foram tratadas com ácido indolbutírico (AIB) nas concentrações de 0;2.000; 4.000 e $6.000 \mathrm{mg} . \mathrm{L}^{-1}$ por 10 segundos. Como substrato, utilizou-se da mistura de vermiculita e areia grossa $(2: 1 \mathrm{v} / \mathrm{v})$, sendo a mesma umedecida com meio contendo solução salina MS e sacarose $1 \%$. As estacas permaneceram por 42 dias dentro de estufas tipo B.O.D. (temperatura de $25^{\circ} \mathrm{C}$, umidade relativa do ar de $90 \%$ e fotoperíodo de 8 horas) e de telado com irrigação por microaspersão, sem controle ambiental. Em ambiente controlado de estufa, as estacas não-tratadas com AIB iniciaram intensa brotação das gemas e formação de calo após sete dias do plantio. Já em ambiente de telado, essas estacas demoraram 21 dias para o início de brotação das gemas, mostrando menor desenvolvimento de calo. Nas estacas tratadas com AIB, os calos surgiram nas regiões dos cortes após o terceiro dia de incubação na estufa B.O.D. As raízes desenvolveram-se a partir dos tecidos da base e dos calos, tornando-se mais nítidas a partir de 14 e 28 dias, respectivamente, para os ambientes de estufa e de telado. Após 42 dias, o melhor percentual de enraizamento (83\%) foi verificado no tratamento com AIB a 2.000 mg. $\mathrm{L}^{-1}$, em ambiente de estufa B.O.D. O emprego dessa estufa, com temperatura, luz e umidade relativa controladas, mostrou-se viável em relação ao telado, no processo de enraizamento das estacas lenhosas da pereira 'Limeira', podendo favorecer o sistema de propagação vegetativa da pereira e encurtar o período da formação de mudas.

Termos para indexação: propagação vegetativa, estaquia e ácido indolbutírico.

\section{ROOTING OF HARDWOOD CUTTINGS OF PEAR TREE WITH IBA UNDER B.O.D. CHAMBER AND GREENHOUSE ENVIRONMENT}

\begin{abstract}
The rooting of cuttings pear under controlled environment of chamber (B.O.D. type) and greenhouse was searched. Hardwood cuttings of 'Limeira' pear, without leaves, measuring $25 \mathrm{~cm}$ of length, were treated with 0, 2000, $4000 \mathrm{and} 6000 \mathrm{mg} . \mathrm{L}^{-1}$ of indolbutyric acid (IBA), for 10 seconds. The vermiculite and sand mixture substrate $(2: 1 \mathrm{v} / \mathrm{v})$ was used and humidified with half contends MS saline solution and sucrose $1 \%$. The cutting stayed per 42 days inside both B.O.D. chamber (temperature of $25^{\circ} \mathrm{C}$, relative humidity of $90 \%$ and photoperiod of 8 hours) and greenhouse with irrigation for aspersion, without environmental control. In B.O.D chamber, the cuttings not treated with IBA began an intense sprouting of the buds and callus formation after seven days of planting. On the other hand in greenhouse atmosphere, those cuttings delayed 21 days for the beginning of the bud sprouting, showing smaller callus development. In the cuttings treated with IBA, the callus appeared in the areas of the cuts after the third day of incubation in the stove B.O.D. The roots were developed starting from the tissues of the base and of the callus, becoming clearer from the $14^{\text {th }}$ and $28^{\text {th }}$ day, respectively, for the stove atmosphere and of greenhouse. After 42 days, the best rooting percentage $(83 \%)$ was verified in the treatment with IBA at $2000 \mathrm{mg} . \mathrm{L}^{-1}$, in B.O.D chamber atmosphere. The utilization of B.O.D chamber, with controlled temperature, light and relative humidity, showed to be more advantageous than the process of greenhouse in the rooting of woody cutting of the 'Limeira' pear tree, that could favor the system of vegetative propagation of the pear tree and to shorten the period of formation of young plants. Index terms: vegetative propagation, cutting and indolbutyric acid.
\end{abstract}

\footnotetext{
'( Trabalho 198-06). Recebido em :29-11-2006. Aceito para publicação em : 22-06-2007. Realizado com apoio financeiro do CNPq.

${ }^{2}$ Pesquisador Científico, Instituto Agronômico (IAC), Caixa Postal 28, 13001-970, Campinas-SP. Com bolsa de produtividade em pesquisa do CNPq. E-mail: wbarbosa@iac.sp.gov.br veiga@iac.sp.gov.br

${ }^{3}$ Professor Adjunto de Fruticultura da Universidade Estadual do Oeste do Paraná (UNIOESTE), Caixa Postal 1008, 95860-000, Marechal Cândido RondonPR. E-mail: rafaelpio@hotmail.com

${ }^{4}$ Pesquisador Científico, Pólo APTA Regional Sudoeste Paulista, E-mail: nelson.pires@aptaregional.sp.gov.br

${ }_{5}^{5}$ Pesquisador Científico, Instituto Agronômico (IAC), Caixa Postal 11, 13214-820, Jundiaí-SP. E-mail: echagas@iac.sp.gov.br
}

Rev. Bras. Frutic., Jaboticabal - SP, v. 29, n. 3, p. 589-594, Dezembro 2007 


\section{INTRODUÇÃO}

No Brasil, as tentativas de se propagarem frutíferas de clima temperado por meio de estacas enraizadas, vêm obtendo sucesso para várias espécies, principalmente as dos gêneros Vitis, Prunus, Malus e Ficus. A maioria das pesquisas, envolvendo esses grupos botânicos, tem como referência básica o uso de estacas lenhosas ou semilenhosas submetidas a tratamentos rizogênicos com AIB em altas concentrações, sob imersão rápida (Biasi et al., 1997; Nacthigal \& Pereira, 2000; Tonietto et al., 2001; Pio et al., 2005). Pelos dados apresentados por esses autores, verifica-se que o percentual de enraizamento pode variar significativamente, dependendo do tipo de estaca, das condições ambientais e do substrato de plantio. Além disso, o conceito de fácil, médio ou difícil enraizamento das estacas pode ser devido à interação de diversos fatores e não somente das características genéticas das cultivares (Fachinello et al., 1995).

Para as espécies de pereira, os trabalhos relatam a possibilidade de haver grande variação no enraizamento, dependendo do ambiente experimental, da época de coleta das estacas e da cultivar utilizada. Os porta-enxertos 'Taiwan NashiC' (Pyrus calleryana Decne.) e pêra 'D'água' (P. communis L.) possuem a característica de médio a difícil enraizamento. Murata et al. (2003), trabalhando com estacas lenhosas desses portaenxertos, mantidas em ambiente de estufa com nebulização intermitente, obtiveram enraizamento próximo a $50 \%$. Já para 'Manshu Mamenashi' ( $P$. betulaefolia L.), esses autores relatam enraizamento quase nulo das estacas, mesmo quando fizeram incisões em sua base. $\mathrm{O}$ ambiente nebulizado, ao que parece, pode melhorar significativamente a capacidade rizogênica da pêra 'D'água', pois, na ausência dessas condições, essa cultivar apresentou enraizamento de apenas 3\% das estacas lenhosas (Ojima \& Rigitano, 1970). Em 'Taiwan Nashi-C', segundo Antunes et al. (1996), mesmo tratando as estacas semilenhosas com AIB a $2.000 \mathrm{mg} . \mathrm{L}^{-1}$ e mantendo-as em ambiente nebulizado, não há promoção de altos índices de enraizamento. Nessas condições, o porta-enxerto apresentou enraizamento da ordem de $46 \%$. Simonetto (1990), ao enraizar estacas lenhosas de 'Manshu Mamenashi', obteve maior sucesso utilizando $3.000 \mathrm{mg} . \mathrm{L}^{-1}$ de AIB. Esse autor notou, porém, que o poder de enraizamento desse porta-enxerto foi reduzindo à medida que se retardava a coleta das estacas. O enraizamento variou de 75,$8 ; 46,1$ e $8,7 \%$, quando trabalhou com estacas coletadas nas primeiras quinzenas de julho, agosto e setembro, respectivamente. Silva et al. (1997), ao enraizarem estacas de pereira enxertadas e tratadas com AIB a $2.000 \mathrm{mg} . \mathrm{L}^{-1}$, verificaram melhor capacidade rizogênica de material da espécie Pyrus calleryana Decne. Estacas dessa espécie, enxertadas em agosto com a pêra Bartlett e plantadas diretamente no viveiro, proporcionaram enraizamento de até $62 \%$. Ao empregarem material da espécie $P$. betulaefolia Bunge, esses autores relatam taxas de enraizamento das estacas abaixo de $30 \%$. Em relação à propagação vegetativa tradicional, nenhum dos trabalhos consultados relata altos percentuais de enraizamento de estacas de porta-enxertos de pereira. No entanto, Sczepanski (2001) ressalta que não se deve levar em consideração apenas o alto percentual de enraizamento obtido nas estacas, mas também o número e a qualidade das raízes formadas pelas mesmas.

Para outras espécies frutíferas lenhosas, o ambiente controlado de casa de vegetação e o tipo de substrato podem proporcionar melhores porcentagens de enraizamento e de sobrevivência das estacas. Duarte et al. (1997), ao propagarem, por exemplo, estacas de jabuticabeira, concluíram que o ambiente controlado de câmara hermeticamente fechada proporcionou o melhor resultado. Discutem os autores que a água fria da estufa com nebulização intermitente pode ser a responsável pelo ineficiente enraizamento das estacas. Já na câmara hermética, o substrato permanecia entre 30 e $35^{\circ} \mathrm{C}$ e a temperatura do ar com 27 a $32^{\circ} \mathrm{C}$, com $100 \%$ de umidade. Quanto ao substrato, Pereira (2003) concluiu que a areia grossa e a vermiculita, quando combinadas com $\mathrm{pH}$ entre 4,5 e 5,5, proporcionam os melhores percentuais de enraizamento das estacas apicais da jabuticabeira 'Sabará'.

Pelo método de propagação vegetativa in vitro, são encontrados resultados de enraizamento bem mais expressivos com as frutíferas de clima temperado, tanto no Brasil como no exterior. Em macieira, pereira e figueira, já se estabeleceram protocolos para pleno desenvolvimento das plantas, com praticamente $100 \%$ de enraizamento dos explantes (Zimmerman, 1984; Barbosa et al., 1996; Nobre \& Romano, 1998; Radmann et al., 2002). A eficiência desse método deve-se às condições ideais do meio de cultivo (solução salina, fontes de carbono, reguladores de crescimento, $\mathrm{pH}$ ) e do ambiente controlado (luz, temperatura, umidade relativa do ar, assepsia). Daí o desenvolvimento deste trabalho que, através da simulação de algumas condições ambientais da cultura in vitro, objetiva melhorar os índices de enraizamento das estacas lenhosas de pereira.

\section{MATERIAL E MÉTODOS}

Utilizou-se, no presente experimento, a pereira 'Limeira', híbrida entre as espécies Pyrus pyrifolia (Burm.f.) Nakai e $P$. communis L., extremamente rústica e empregada para fins culinários e para porta-enxerto. Ramos lenhosos dessa cultivar foram coletados de plantas adultas, em fins de agosto de 2006, durante o inverno subtropical do Estado de São Paulo. Em seguida à coleta, esses foram envolvidos em jornal umedecido, acondicionados em sacos plásticos e levados ao laboratório de propagação do Núcleo Jardim Botânico, do Instituto Agronômico (IAC). No dia seguinte, após cortado na forma de estacas, medindo $25 \mathrm{~cm}$ de comprimento e 8 a $12 \mathrm{~mm}$ de diâmetro, contendo de 4 a 6 gemas cada e sem folhas, o material foi imerso em solução de ácido ascórbico (200 mg. $\left.\mathrm{L}^{-1}\right)$ por 30 minutos. Em ambas as extremidades das estacas, foram realizados cortes em bisel, próximos às gemas.

As estacas, após tratadas com AIB nas concentrações de $0 ; 2.000 ; 4.000$ e $6.000 \mathrm{mg} . \mathrm{L}^{-1}$, por 10 segundos, foram enterradas em sacos plásticos perfurados contendo vermiculita e areia grossa $(2: 1 \mathrm{v} / \mathrm{v})$, em $50 \%$ de seu comprimento. O substrato foi umedecido semanalmente com solução salina MS (Murashige \& Skoog, 1962), reduzindo pela metade a sua concentração e acrescida de sacarose a $1 \%$, sendo o $\mathrm{pH}$ elevado a 5,5 . Em seguida, as estacas foram mantidas em estufas tipo B.O.D. (com temperatura de $25^{\circ} \mathrm{C}$, umidade relativa do ar de $90 \%$ e fotoperíodo de 8 horas) e em 
telado sem controle ambiental e dotado de irrigação por microaspersão ( 1 minuto a cada $1 / 2$ hora). $O$ delineamento experimental adotado foi o inteiramente casualizado, no esquema fatorial 4 × 2 (concentrações de AIB e ambientes de enraizamento), com quatro repetições e 20 estacas por parcela.

O material permaneceu nesses dois ambientes por 42 dias, sendo avaliadas posteriormente as características não-destrutivas: porcentagens de estacas enraizadas, calejadas, vivas sem calos e raízes, e o número médio de raízes por estaca. No entanto, a cada sete dias, as estacas eram avaliadas qualitativamente quanto à formação e aspecto de calos e raízes, à exceção da primeira semana, quando receberam avaliação diária. Os dados foram submetidos à análise de variância, as médias ao teste Tukey e as concentrações de AIB à regressão (Gomes, 2000). As análises estatísticas foram realizadas pelo programa computacional Sistema para Análise de Variância - SISVAR (Ferreira, 2000).

\section{RESULTADOS E DISCUSSÃO}

Quanto à análise dos dados, houve diferença estatística em todas as variáveis analisadas para o ambiente de enraizamento e concentrações de AIB, e somente interação entre os dois fatores para a porcentagem de estacas enraizadas (Tabela 1).

Em ambiente controlado de estufa tipo B.O.D., notaram-se diferenças na coloração e no tipo dos calos desenvolvidos a partir dos cortes nas extremidades das estacas. Os calos apresentaram-se mais volumosos e creme-amarelados na base das estacas. Na extremidade apical das mesmas, ocorreu formação de calos esbranquiçados e menos salientes. As estacas nãoexpostas ao AIB iniciaram a brotação das gemas e a formação de calo após sete dias de permanência na estufa tipo B.O.D. Já em ambiente de telado, não se verificaram tecidos calosos na porção apical das estacas, mas somente na extremidade basal. Nesse ambiente, as estacas demoraram 21 dias, em média, para o início de brotação das gemas, apresentando formação de calo a partir do $14^{\circ}$ dia do plantio. Já as raízes, somente foram visualizadas após o $21^{\circ}$ dia do plantio.

Outro fato interessante observado foi que, para as estacas tratadas com AIB, os calos surgiram mais precocemente, independentemente da concentração utilizada. Já, a partir do terceiro dia de incubação na estufa B.O.D., foi possível visualizar a formação de calos na região dos cortes, em ambas as extremidades das estacas. Segundo Grattapaglia \& Machado (1990; 1998), a duração da rizogênese pode variar de uma a três semanas, sendo que, para as fases de indução e iniciação, a presença da auxina é fundamental, enquanto para o crescimento das raízes, essa se torna inibidora.

Ao que parece, as condições propícias da estufa e o aumento da concentração da auxina na base da estaca estimularam a rápida formação de calo. Segundo Fachinello et al. (1995), o calo forma-se quando há lesionamento dos tecidos do xilema e do floema, resultando em posterior cicatrização dos mesmos, constituído por uma massa de células parenquimatosas, desorganizadas e em diferentes etapas de lignificação. Todas as estacas que desenvolveram raízes, apresentavam calos nas proximidades do corte. Não se observou, portanto, a formação direta de raízes em estacas com ausência de calo. As raízes adventícias foram formadas nas proximidades da região cambial e sobre o tecido caloso. Segundo Hamann (1998), as mudanças anatômicas, durante a formação de raízes adventícias, consistem em quatro estágios mais ou menos descontínuos. São eles: a) proliferação das células na base do corte; b) desdiferenciação do tecido vascular e periderme; c) desdiferenciação de uma zona perto do câmbio e do floema ferido para formar uma raiz inicial; d) formação de um meristema de raiz. Aos 42 dias após o início do experimento, as estacas já não mostravam mais indícios de formação substanciosa de calos e de raízes primárias, pois o aspecto e a quantidade desses eram praticamente os mesmos da avaliação anterior. Nos dois ambientes pesquisados, $100 \%$ das estacas emitiram brotações em gemas situadas em sua porção apical; nenhuma morte ou seca parcial dos tecidos foi verificada no período.

Os melhores percentuais de enraizamento foram verificados nas estacas mantidas em ambiente controlado de estufa B.O.D. Pelos dados de regressão, verifica-se que o melhor percentual de enraizamento foi proporcionado na concentração de 4.000 mg.L.-1 de AIB (Figura 1). Já, em ambiente de telado, houve aumento linear da porcentagem de enraizamento, em função das aplicações crescentes das concentrações de AIB, ao passo que estacas tratadas com $6.000 \mathrm{mg} . \mathrm{L}^{-1}$ de AIB apresentaram $37,52 \%$ de enraizamento (Figura 1). Quanto ao número de raízes por estacas, a concentração de $4.000 \mathrm{mg} . \mathrm{L}^{-1}$ de AIB também proporcionou melhores resultados $(7,54)$ (Figura 4).

Quanto à formação de calos, menores porcentagens foram obtidas com $2.000 \mathrm{mg} . \mathrm{L}^{-1}$ de AIB; isso talvez justifique a maior porcentagem de enraizamento das estacas nessa concentração (Figura 2). O mesmo ocorreu para a porcentagem de estacas vivas, sem raízes e sem calos (Figura 3).

Levando em consideração o ambiente de enraizamento, ficou evidenciado neste trabalho que a utilização de B.O.D., como ambiente de enraizamento, promoveu aumento de $47,19 \%$ de estacas enraizadas, já que as estacas colocadas em B.O.D. apresentaram, na média, $73,12 \%$ de estacas enraizadas, contra $25,93 \%$ de enraizamento médio para as estacas colocadas em telado (Tabela 2). Alvarenga \& Carvalho (1983) relatam que o AIB é uma substância mais estável e efetiva na promoção do desenvolvimento de raízes; a sua molécula passa rapidamente nos diferentes tecidos da planta, sendo inativada de forma relativamente lenta pelos sistemas de enzimas oxidativas de auxinas. Neste experimento, ocorreu um rápido e profuso crescimento de calo na base das estacas tratadas com $6.000 \mathrm{mg} . \mathrm{L}-$ ${ }^{1}$ de AIB. Isso, porém, não prejudicou a formação de raízes nos tecidos adjacentes, principalmente no ambiente controlado. Esse fato é amplamente discutido na literatura, em que as altas concentrações de auxinas são responsáveis pela maior formação de calos, sendo prejudicial à indução e ao desenvolvimento de raízes (Fortes, 1992).

Das estacas colocadas em B.O.D., 73,12\% enraizaram, $22,81 \%$ delas apresentaram somente calos e apenas $4,07 \%$ não enraizaram nem calejaram. Nas estacas colocadas em telado, o enraizamento foi de apenas $25,93 \%$ e o calejamento foi de $14,68 \%$; isso propiciou um montante de $59,39 \%$ de estacas que não 
mostraram quaisquer indícios visíveis de enraizamento até $042^{\circ}$ dia do experimento (Tabela 2).

Sem dúvida, o ambiente controlado da estufa tipo B.O.D. e, possivelmente, os suplementos inorgânicos e orgânicos, incorporados semanalmente ao substrato, proporcionaram aceleração nas atividades mitóticas e nas mudanças metabólicas das células. Segundo Assis \& Teixeira (1998), nas condições in vitro, a formação de raízes é um processo que requer muita energia. Daí o fornecimento de carboidratos é quase sempre necessário, visto que a fotossíntese realizada pelos explantes é relativamente baixa. Assim, neste experimento, a presença da sacarose pode ter auxiliado no processo de enraizamento das estacas, mesmo em concentração reduzida $\left(10\right.$ g. $\left.\mathrm{L}^{-1}\right)$. Em condições de laboratório, há relatos de que a adição de sacarose é bastante importante ao enraizamento in vitro. Um maior percentual de enraizamento da pereira OH x F97 ocorreu com 20 g.L.-1 de sacarose; a formação de raízes secundárias baixou de $80 \%$ em 30 g.L. $\mathrm{L}^{-1}$ de sacarose para $0 \%$ na ausência de sacarose (Leite et al., 2000). Quanto à porcentagem de enraizamento e de número de raízes por estaca, os resultados obtidos com a pereira 'Limeira', em ambiente B.O.D., podem ser considerados como dos mais significativos da fruticultura nacional (Figuras 1 e 4). Até o momento, os maiores índices de enraizamento de pereira (entre 80 e $100 \%$ ) somente tinham sido obtidos em condições totalmente controladas de laboratório de micropropagação (Pasqual \& Lopes, 1991). O aperfeiçoamento das técnicas de propagação de porta-enxertos de pereira deve ser incentivado, pois a redução do prazo total na formação das mudas enxertadas tem sido bastante demandada atualmente (Barbosa et al., 1998). Ao se proceder a enxertia das cultivares-copa em estacas enraizadas, há uma redução considerável no prazo de permanência das mudas no viveiro. As mudas de pereira, formadas a partir de porta-enxertos originados de sementes, necessitam de 15 a 20 meses para alcançarem os padrões desejados pelo mercado (Barbosa et al., 1996). Já as mudas de pereira, formadas a partir de estacas lenhosas com 20-25 cm de comprimento e 10-12 mm de diâmetro, poderão alcançar os padrões desejados para plantio em campo entre 4 e 8 meses. Se enxertadas, o prazo para a formação das mudas poderá ser de 6-8 meses.

TABELA 1 - Análise de variância para porcentagem média de estacas enraizadas (PEE), calejadas (PEC), vivas sem raízes e calos (PEV), e número médio de raízes por estacas de pereira 'Limeira' em diferentes ambientes. IAC, Campinas-SP, 2006.

\begin{tabular}{lllll}
\hline Causas da variação & PEE & PEC & PEV & NRE \\
\hline Ambiente & $7813,28^{*}$ & $528,12^{*}$ & $52,53^{*}$ & $4475,78^{*}$ \\
AIB & $1040,36^{*}$ & $245,83^{*}$ & $38,44^{*}$ & $363,28^{*}$ \\
Ambiente x AIB & $1046,61^{*}$ & $194,79^{\text {NS }}$ & $21,19^{\text {NS }}$ & $169,53^{\text {NS }}$ \\
cv (\%) & 17,70 & 20,89 & 23,26 & 23,90 \\
\hline
\end{tabular}

ns: não significativo.

*: significativo $(P<0,05)$
TABELA 2 - Porcentagem média de estacas enraizadas (PEE), calejadas (PEC), vivas sem raízes e calos (PEV), e número médio de raízes por estacas de pereira 'Limeira' em diferentes ambientes. IAC, CampinasSP, 2006.

\begin{tabular}{|c|c|c|c|c|}
\hline \multirow[t]{2}{*}{ Ambiente de enraizamento } & \multicolumn{4}{|c|}{ Variável Analisada* } \\
\hline & PEE & PEC & PEV & NRE \\
\hline B.O.D. & $73,12 \mathrm{a}$ & 22,81 a & $4,07 \mathrm{~b}$ & 7,68 a \\
\hline Telado & $25,93 \mathrm{~b}$ & $14,68 \mathrm{~b}$ & $59,39 \quad \mathrm{a}$ & $5,12 \mathrm{~b}$ \\
\hline cv $(\%)$ & 17,70 & 20,89 & 23,26 & 23,90 \\
\hline
\end{tabular}

* Médias seguidas da mesma letra na coluna não diferem significamente entre si, pelo teste de Tukey, a 5\% de probabilidade.

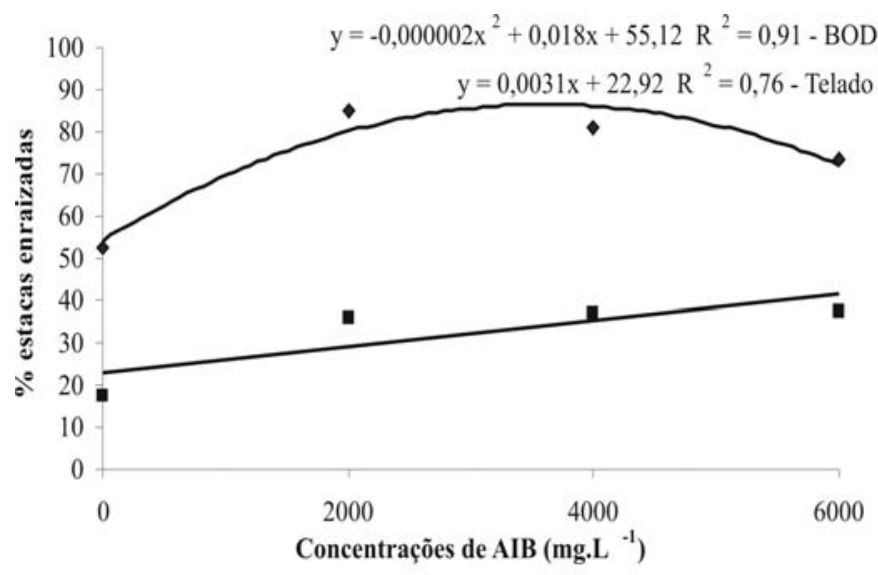

FIGURA 1 - Porcentagem média de estacas enraizadas de pereira 'Limeira' tratadas com diferentes concentrações de AIB, em dois diferentes ambientes de enraizamento ( B.O.D. telado ). IAC, Campinas-SP, 2006.

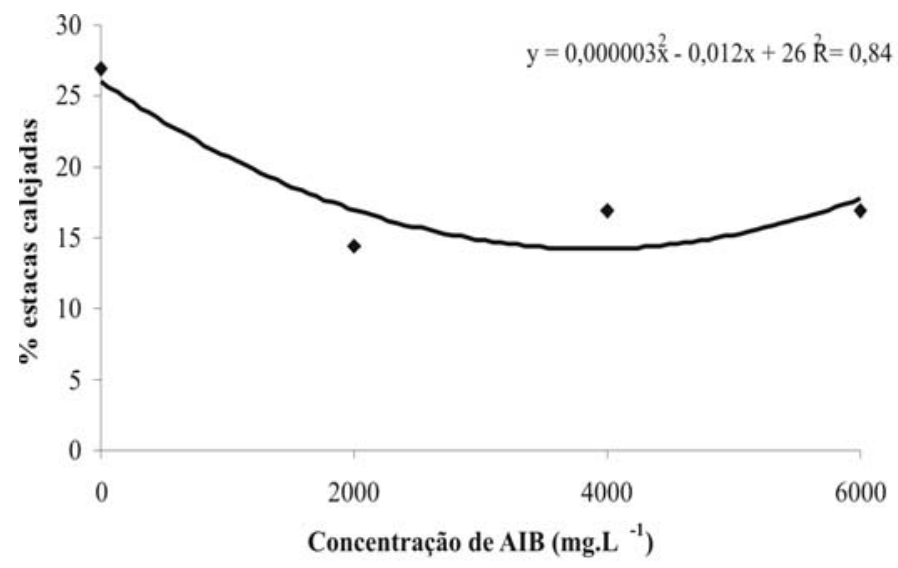

FIGURA 2 - Porcentagem média de estacas calejadas de pereira 'Limeira' tratadas com diferentes concentrações de AIB. IAC, Campinas-SP, 2006. 


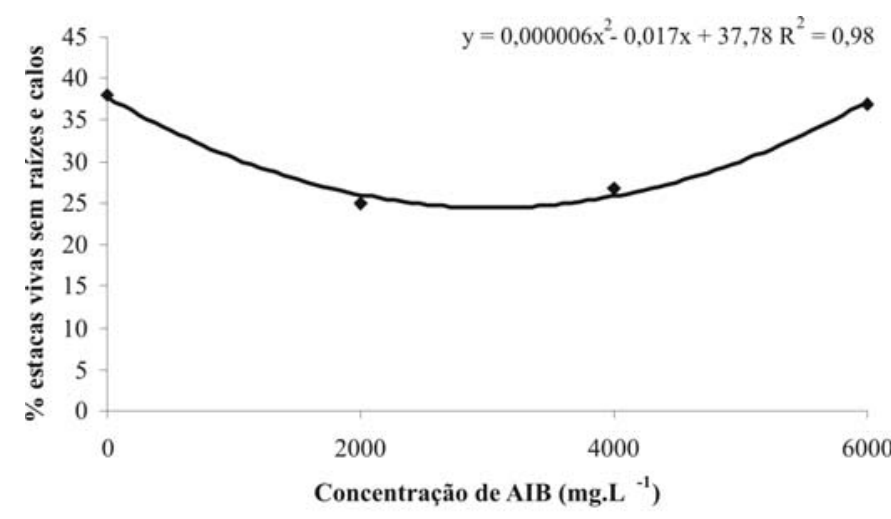

FIGURA 3 - Porcentagem média de estacas vivas sem raízes e calos de pereira 'Limeira' tratadas com diferentes concentrações de AIB. IAC, Campinas-SP, 2006.

\section{CONCLUSÕES}

1- A utilização do AIB proporciona altos percentuais de enraizamento nas estacas lenhosas da pereira 'Limeira', principalmente quando em estufa tipo B.O.D.

2- Na pereira cv. Limeira, o melhor enraizamento e número de raízes são obtidos quando as estacas são tratadas com AIB (4000 mg.L $\mathrm{L}^{-1}$ ) e mantidas em ambiente de estufa tipo B.O.D.

\section{REFERÊNCIAS}

ALVARENGA, L.R.; CARVALHO, V.D. Uso de substâncias promotoras de enraizamento de estacas de frutíferas. Informe Agropecuário, Belo Horizonte, v.9, n.101, p.47- 55, 1983.

ANTUNES, L.E.C.; HOFMANN, A.; RAMOS, J.D.; CHALFUN, N.N.J.; OLIVEIRA JÚNIOR, A.F. Efeito de aplicação de concentração de ácido indolbutírico no enraizamento de estacas semilenhosas de Pyrus calleryana. Revista Brasileira de Fruticultura, Jaboticabal, v.18, n.3, p.371-376, 1996.

ASSIS, T.F.; TEIXEIRA, S.L. Enraizamento de plantas lenhosas. In: TORRES, A.C.; CALDAS, L.S., BUSO, J.A. Cultura de tecidos e transformação genética de plantas. Brasília: Embrapa-SPI/ Embrapa-CNPH, 1998. p.261-296.

BARBOSA, W.; CAMPO DALL'ORTO, F.A.; OJIMA, M.; MARTINS, F.P.; CASTRO, J.L. Desenvolvimento de cultivares e espécies de pereira enxertadas em plântulas de Taiwan Nashi-C na fase de formação de mudas. Bragantia, Campinas, v.55, n.2, p.341-345, 1996.

BARBOSA, W.; CAMPO DALL'ORTO, F.A.; OJIMA, M.; MARTINS, F.P.; CASTRO, J.L.; MARTINS, A.L.M.; SANTOS, R.R. Formação rápida de mudas vigorosas de pêra com portaenxerto oriental. OAgronômico, Campinas, v.47-50, p.28-31, 1998.

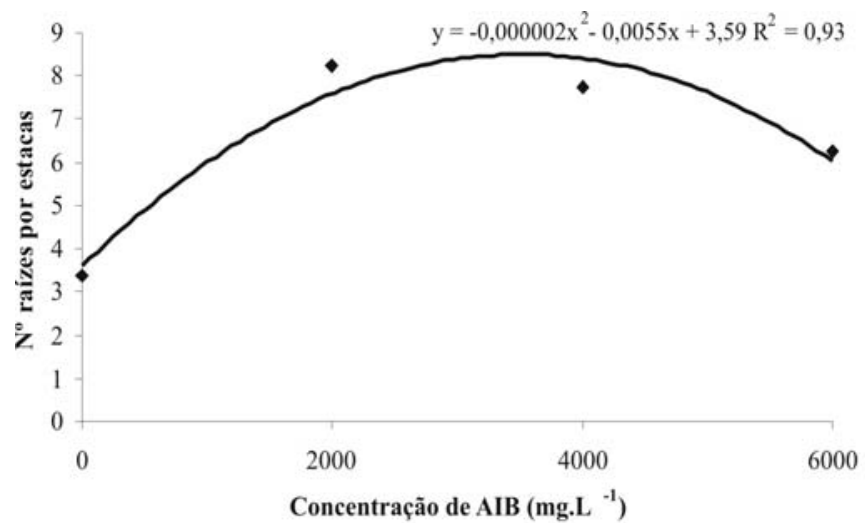

FIGURA 4 - Número médio de raízes por estacas de pereira 'Limeira' tratadas com diferentes concentrações de AIB. IAC, Campinas-SP, 2006.

BIASI, L.A.; POMMER, C.V.; PINO, P.A.G.S. Propagação de portaenxertos de videira mediante estaquia semilenhosa. Bragantia, Campinas, v.56, n.2, p.367-376, 1997.

DUARTE, O.; LUDDERS, P.; HUETE, M. Propagation of Jaboticaba by terminal leafy cuttings. Acta Horticul-turae, Wageningen, n.452, p.123-128, 1997.

FACHINELLO, J.C.; HOFFMANN, A.; NACHTIGAL, J.C.; KERSTEN, E.; FORTES, G.R.L. Propagação de plantas frutíferas de clima temperado. 2. ed. Pelotas: UFPEL, 1995. 178p.

FERREIRA, D.F. Análise estatística por meio do SISVAR (Sistema para Análise de Variância) para Windows versão 4.0. In: REUNIÃO ANUAL DA REGIÃO BRASILEIRA DA SOCIEDADE INTERNACIONAL DE BIOMETRIA, 45., 2000, São Carlos. Anais... São Carlos: UFSCar, 2000. p.255-258

FORTES, G.R.L. Calogênese e organogênese "in vitro" de macieira (Malus spp.) afetadas por fatores físicos, químicos e biológicos. 1992. 163f. Dissertação. (Doutorado em Agronomia) Universidade Federal de Viçosa, Viçosa, 1992.

GRATTAPAGLIA, D.; MACHADO, M.A. Micropropagação. In: TORRES, C.A.; CALDAS, L.S. Técnicas e aplicações da cultura de tecidos de plantas. Brasília. ABCTP/EMBRAPA-CNPH, 1990. p.99-169.

GRATTAPAGLIA, D.; MACHADO, M.A. Micropropagação. In: TORRES, A.C.; CALDAS, L.S.; BUSO, J.A. Cultura de tecidos e transformação genética de plantas. Brasília: Embrapa-SPI/ Embrapa-CNPH, 1998. p.183-260.

GOMES, F.P. Curso de estatística experimental. 14. ed. Piracicaba: USP/ESALQ, 2000.477p.. 
HAMANN, A. Adventitious root formation in cuttings of loblolly pine (Pinus taeda L.): developmental sequence and effects of maturation. Trees -Structure and Function, Berlin, v.12, n.3, p.175$180,1998$.

LEITE, G.B.; FINARDI, N.; FORTES, G.R.L. Efeitos de concentrações de sacarose no meio de cultura e da intensidade luminosa no enraizamento in vitro do porta-enxerto de pereira OH x F97. Ciência e Agrotecnologia, Lavras, v.24, n.2, p.353-357, 2000.

MURASHIGE, T.; SKOOG, F. A revised medium for rapid growth and biossays with tobacco tissue cultures. Physiologia Plantarum, Edinburg, v.15, p.473-479, 1962.

MURATA, I.M.; BARBOSA, W.; NEVES, C.S.V.J.; FRANCO, J.A.M. Enraizamento de estacas lenhosas de porta-enxertos de pereira sob nebulização intermitente. Revista Brasileira de Fruticultura, Jaboticabal, v.24, n.2., p.583-585, 2002.

NACTHIGAL, J.C.; PEREIRA, F.M. Propagação do pessegueiro (Prunus persica (L.) Batsch) cv. Okinawa por meio de estacas herbáceas em câmara de nebulização em Jaboticabal-SP. Revista Brasileira de Fruticultura, Jaboticabal, v.22, n.2, p.208-212, 2000. NOBRE, J.; ROMANO, A. In vitro cloning of Ficus carica L. adult trees. Acta Horticulturae, Wageningen, v.480, p.161-164, 1998.

OJIMA, M.; RIGITANO, O. Clones para porta-enxerto da pereira. Bragantia, Campinas, v.29, n.26, p.287-292, 1970.

PASQUAL, M.; LOPES, P.A. Influência de diversos fatores sobre o enraizamento do porta-enxerto de pereira (Pyrus calleryana) in vitro. Pesquisa Agropecuária Brasileira, Brasília, v.26, n.3, p.331334, 1991.

PEREIRA, M. Propagação via estacas apicais, caracterização morfológica e molecular de jabuticabeiras (Myrciaria spp). 2003. $86 \mathrm{f}$. Tese (Doutorado em Agronomia) - Escola Superior de Agronomia "Luiz de Queiroz", Universidade de São Paulo, Piracicaba, 2003.
PIO, R.; BASTOS, D.C.; ALVES, A.S.R.; ENTELMANN, F.A.; SCARPARE FILHO, J.A.; MOURÃO FILHO, F.A.A.; ALVARENGA, A.A.; ABRAHÃO, E. Enraizamento de estacas semilenhosas de marmeleiro. Revista Científica Rural, Bagé, v.10, n.1, p.116-121, 2005.

RADMANN, E.B.; FACHINELLO, J.C.; PETERS, J.A.Efeito de auxinas e condições de cultivo no enraizamento in vitro de portaenxertos de macieira 'M-9'. Revista Brasileira de Fruticultura, Jaboticabal, v.24, n.3, p. 624-628, 2002.

SCZEPANSKI, P.H.G. Propagação in vitro do porta-enxerto de ameixeira Mirabolano (Prunus cerasifera Ehrh.). 2001. 77 f. Dissertação (Mestrado em Agronomia) - Faculdade de Agronomia “Eliseu Maciel”, Universidade Federal de Pelotas, Pelotas, 2001.

SILVA, E.S.B.; FINARDI, N.L.; FORTES, G.R. Época de enxertia no enraizamento e união do enxerto sobre os porta-enxertos Pyrus calleryana e Pyrus betulaefolia através da enxertia e enraizamento simultâneos. Revista Brasileira de Agrociência, Pelotas, v.3, n.3, p.119-124, 1997.

SIMONETTO, P.R. Propagação de Pyrus calleryana Dene e Pyrus betulaefolia Bunge, porta-enxertos para pereira, através do processo de estaquia. 1990. 59f. Dissertação (Mestrado em Agronomia) - Faculdade de Agronomia "Eliseu Maciel", Universidade Federal de Pelotas, Pelotas, 1990.

TONIETTO, A.; FORTES, G.R.L.; SILVA, J.B. Enraizamento de miniestacas de ameixeira Revista Brasileira de Fruticultura, Jaboticabal, v.23, n.3, p.373-376, 2001.

ZIMMERMAN, R.H. Factors affecting in vitro propagation of apple cultivars. Acta Horticulturae, Wageningen, v.131, p.171178, 1984. 